\title{
MAQUIAVELISMO EM LOJISTAS: UM RETORNO A ORIGEM
}

\section{TENANTS IN MACHIAVELLIANISM: A RETURN TO ORIGIN}

Data de submissão: 29/07/2012 Aceite: 05/04/2014

Jakcilene Dias Rocha ${ }^{1}$ Francisco Roberto Pinto ${ }^{2}$ Joelma Soares da Silva ${ }^{3}$

\section{RESUMO}

O objetivo geral deste artigo é verificar a formação do construto Maquiavelismo nos profissionais do setor lojista cearense. Para tanto, foi realizada uma pesquisa bibliográfica seguida de pesquisa de campo em 164 estabelecimentos do setor lojista de Fortaleza. Foram consultados 400 respondentes, usando a escala Machiavellianism Personality Scale (MPS), desenvolvida por Dahling, Whitaker e Levy (2009). Pelos resultados obtidos, foi possível inferir que o objetivo geral do trabalho foi alcançado quando se obteve a formação dos cinco fatores do maquiavelismo (Amoralidade, Influência Interpessoal, Status, Descrença nos Outros e Individualismo) e constatou-se que o gênero está inter-relacionado com o Maquiavelismo. Tal relação, porém, não foi encontrada quando se verificaram os aspectos de religiosidade, idade e cargo (para gerentes e vendedores). A partir dos resultados apresentados neste estudo, podem-se traçar estratégias para o melhor gerenciamento da colaboração de vendedores e gerentes do comércio lojista, de modo a melhorar as relações interpessoais destes profissionais com seus diversos públicos, bem como, por consequência, otimizar vendas, uma vez que se conhece mais como estes trabalhadores se comportam.

Palavras- Chave: Maquiavelismo. Setor Lojista. Personalidade.

\footnotetext{
${ }^{1}$ Possui graduação em Administração pela Universidade Estadual do Ceará - UECE e mestrado em Administração pela Universidade Estadual do Ceará - UECE. Fortaleza. Ceará. Brasil. E-mail: jakdiasr@hotmail.com

2 Possui graduação em Administração de Empresas pela Universidade Estadual do Ceará - UECE, graduação em Licenciatura em Música pela Universidade Estadual do Ceará - UECE, mestrado em Administração pela Universidade Federal da Paraíba - UFPB, doutorado em Administração pela Universidade Federal da Paraíba - UFPB e doutorado em Gestão de Empresas pela Universidade de Coimbra - UC, Portugal. Atualmente é Professor dos cursos de Graduação e Mestrado em Administração da Universidade Estadual do Ceará (UECE) e Coordenador do Laboratório de Gestão de Pessoas e Sustentabilidade (UECE-LAPES). Fortaleza. Ceará. Brasil. E-mail: rpinto@secrel.com.br ${ }^{3}$ Possui graduação em Secretariado Executivo pela Universidade Federal do Ceará - UFC e mestrado em Administração pela Universidade Estadual do Ceará - UECE. Atualmente é professora assistente e coordenadora do Curso de Secretariado Executivo da Universidade Federal do Ceará e do Núcleo de Estudos e Pesquisas em Secretariado Executivo (NEPES/UFC). Fortaleza. Ceará. Brasil. E-mail: joelma. soares@ufc.br
} 


\begin{abstract}
The purpose of this paper is to verify the formation of the Machiavellianism construct among professionals of merchant industry in the state of Ceará, Brazil. We performed a literature search followed by field research, in 164 shops of Fortaleza. We consulted 400 respondents, using the scale Machiavellianism Personality Scale (MPS), developed by Dahling, Whitaker and Levy (2009). According to the results obtained, it was possible to infer that the general objective of this study was reached when there was the formation of the five factors of Machiavellianism (Amoral, Interpersonal Influence, Status, Individualism and Disbelief in Others) and found that gender is interrelated with the Machiavellianism. This relationship, however, was not found considering religiosity, age and position (for managers and vendors). From the results presented in this study, one can devise strategies to better manage the collaboration of vendors and managers in shops, in order to improve interpersonal relationships of these professionals with its stakeholders and, consequently, optimize sales as are known in behave as these workers.
\end{abstract}

Keywords: Machiavellianism. Personality. Commercial Industry.

\title{
1 INTRODUÇÃO
}

Compreender o comportamento humano, no contexto empresarial, tem sido alvo de diversas pesquisas (e.g. CHANLAT, 1996; CANDEIAS, 1997), pois norteia uma série de inferências acerca do comportamento do homem na própria sociedade e de ações organizacionais, que refletem o comportamento individual de seus dirigentes.

Na perspectiva de análise comportamental, o Maquiavelismo surge como uma variável importante, dada sua forte relação com o comportamento humano, sendo este determinado por avaliações positivas ou negativas da realidade e exposto através das atitudes.

Pesquisas realizadas em outros países, nos últimos 20 anos, demonstram a influência do Maquiavelismo no comportamento das pessoas dentro das organizações. Esses estudos chegaram a diversas conclusões, tais como a relação negativa do Maquiavelismo com a satisfação no trabalho (e.g. GABLE; TOPOL, 1987) e a baixa disposição em ajudar os outros (e.g. WOLFSON, 1981).

Embora o assunto tenha ganhado gradativa repercussão no exterior, no Brasil foram encontradas poucas produções acadêmicas voltadas para o tema (GROHMANN; BATTISTELLA; COSTA, 2010a). A maioria dos estudos realizados sobre o nível de perfil maquiavélico nas organizações ainda utiliza a escala a Mach IV, desenvolvida na década de 1960, que possui problemas de validação estatística, fato que levou à elaboração de uma nova escala de mensuração a $\mathrm{Ma}$ chiavellianism Personality Scale (MPS) de Dahling, Whitaker e Levy (2009). Esta escala foi testada e validada no Brasil por Grohmann, Battistella e Costa (2010a), porém ainda carece de estudos que a consolidem como instrumento de pesquisa válido e largamente aceito.

Diante da percepção desta lacuna, este estudo tem como objetivo geral verificar a formação do construto Maquiavelismo nos profissionais do setor lojista cearense. A relevância de se estudar o comércio do Ceará encontra-se na importância do referido setor para a economia do estado, assim como, na visão empírica, os integrantes desse setor utilizam artimanhas comerciais no convencimento dos clientes, que muitas vezes ultrapassam os limites entendidos como comportamento ético por outras categorias profissionais.

De modo a contribuir para o alcance do objetivo geral, estabeleceram-se algumas hipóteses, cujas validades foram verificadas por essa pesquisa, conforme segue:

$\mathrm{H}_{1}$ : Os gestores são mais maquiavélicos do que seus funcionários

$\mathrm{H}_{2:}$ Os homens são mais maquiavélicos do que as mulheres; 
$\mathrm{H}_{3}$ : Os mais jovens são mais maquiavélicos do que os mais velhos;

$\mathrm{H}_{4}$ : Os que não são religiosos são mais maquiavélicos do que os religiosos.

A importância acadêmica desta pesquisa está no fato de que esse trabalho procura abordar de modo prático o construto "Maquiavelismo", assim como demonstrar o quão o assunto ainda é atual dentro das organizações.

A seguir, faz-se a apresentação do referencial teórico, no qual são abordados os conceitos e outros aspectos teóricos pertinentes ao tema, seguindo-se a descrição dos procedimentos metodológicos que foram utilizados para o alcance do objetivo deste trabalho; posteriormente, são apresentados e analisados os resultados e, na sequência, está a conclusão, seguida das referências das fontes teóricas utilizadas como base para o estudo.

\section{REFERENCIAL TEÓRICO}

A literatura base revisada para fundamentação deste trabalho encontra-se organizada mediante a exploração de quatro aspectos-chave para a compreensão das análises e discussões: uma abordagem sobre o livro O Príncipe, de Maquiavel; a conceituação de Personalidade Maquiavélica; a delimitação do que é o Maquiavelismo nas organizações; o detalhamento sobre a MPS. Esta divisão resulta na denominação dos subitens que compõem esta revisão teórica, como se vê a seguir. Trabalhar esses conceitos proporciona embasamento teórico para o desenvolvimento desta pesquisa.

\subsection{O Príncipe}

Maquiavel, em sua mais famosa obra, O Príncipe construída na forma de aconselhamento, inspirada em Lorenzo II, da tradicional família de Médici, aborda meios e comportamentos ideais para um governante conquistar ou continuar no poder. O principado citado no opúsculo não se trata de um Estado ou de um Reino, mas um regime político (MARTINS, 2008). O livro O Príncipe, conforme o entendimento de Barros (2008) tem por objetivo pensar, do ponto de vista dos ocupantes do poder, como a tarefa de governar é cheia de obstáculos que, se não forem enfrentados corretamente, podem acarretar a derrota política.

Segundo Martins (2008) o principal norteador do pensamento político de Maquiavel é a noção de que em todo Estado há essencialmente dois grandes interesses em conflito: o dos ricos, que desejam comandar, e dos pobres, que desejam não ser oprimidos.

Baseando-se neste horizonte, Maquiavel (1982) traça diretrizes contundentes e necessárias para um governo eficaz. Dentre muitas lições, que merecem destaques neste estudo, apontamos a seguinte: fazer o mal é por vezes necessário para consolidar e fortalecer o poder; mesmo necessário, o mal deve ser feito de uma única vez, para não despertar reações; o bem deve ser feito aos poucos, para que possa ser valorizado.

Ainda que não menos expressiva, mas se referindo à gestão de cada reino, o autor reforça a importância de o conquistador residir no lugar conquistado, pois sua presença poderá prevenir ou contornar desordens. Nesse sentido, ressalte-se também a necessidade do governante apoiar os menos poderosos, sem lhes aumentar o poder nem enfraquecer os poderosos (MAQUIAVEL, 1982).

É lícito ressaltar as orientações depreendidas aos exércitos de um reino. Conforme Maquiavel (1982), a experiência ensina que apenas os príncipes e as repúblicas que possuíam exércitos 
próprios tiveram grandes sucessos. Acrescendo a esta constatação, o referido autor prossegue afirmando que apoiadores das forças mercenárias sempre sofreram danos, sendo prudente ao príncipe manter e subsidiar seu próprio exército, a fim de ter maior controle e poder sobre seu Estado.

No tocante à escolha de seus ministros, a obra ilustra um método norteador do reconhecimento um ministro por parte do príncipe: se o ministro preocupa-se mais consigo do que com o príncipe, nunca será um bom ministro, pois quem tem em suas mãos um Estado não deve pensar em si próprio, mas no monarca. Por outro lado, o príncipe deve assegurar a fidelidade do ministro, honrando-o, enriquecendo-o e fazendo-lhe favores (MAQUIAVEL, 1982).

Outra orientação relevante contida na obra O Príncipe é o mecanismo do encantamento do povo por meio de festas e espetáculos, pois nada torna um príncipe mais querido e adorado do que realizar grandes empreendimentos em certas épocas do ano. Ainda conforme Maquiavel (1982), a melhor defesa que existe para um rei é não ser odiado pelo seu povo, pois ainda que este tenha fortalezas ou muralhas se o povo o odiar, estas não o salvarão.

Um príncipe não precisa ter qualidades como piedade, fé, integridade, humanidade e religião, mas é indispensável parecer tê-las. Deste modo, "o príncipe deve ser raposa para conhecer os laços e leão para aterrorizar os inimigos" (MAQUIAVEL, 1982). Um príncipe deve ser ponderado em seu pensamento e ação, não ter medo de si mesmo e proceder de forma equilibrada, com prudência e humanidade, para que a excessiva confiança não o torne incauto, nem a exagerada desconfiança o faça intolerável (MAQUIAVEL, 1982). Vislumbra-se, deste modo, a perspectiva de comportamentos com características específicas, as quais o autor nomeia como virtú.

A noção de virtú, pensada por Maquiavel, pode ser enunciada como o conjunto de qualidades políticas necessárias ao bom governo e à conservação do Estado (MARTINS, 2008). Esse conjunto de comportamentos e qualidades relevantes a um bom principado posteriormente receberá uma nova abordagem e a uma nova nomenclatura: Personalidade Maquiavélica.

\subsection{Personalidade Maquiavélica}

Nascido a partir da obra O Príncipe (MAQUIAVEL, 1982), publicado pela primeira vez em 1532, na Itália, o termo Maquiavelismo passou a ser tratado durante anos como sinônimo de algo amoral e antiético. Sendo cada vez mais incorporado ao vocabulário nacional, o Maquiavelismo passou a ser compreendido como aquilo que envolve perfídia, falsidade e dolo, caracterizando-se pela astúcia, duplicidade, má fé, ardil e velhacaria (HOUAISS, 2001). Verifica-se que tais definições demonstram as conotações negativas dadas ao termo.

Conforme Christie e Geis (1970), os indivíduos com perfil maquiavélico não são necessariamente imorais, porém apresentam pouco afeto nas relações interpessoais e pouca preocupação com a ética convencional. Corroborando com tal assertiva, Gable e Dangelo (1994 apud LUSTOSA; ROAZZI; CAMINO, 2004) acreditam que os indivíduos maquiavélicos devem ser vistos não como antiéticos, mas como pessoas capazes de sacrificar a ética segundo seus interesses.

Quanto aos fatores que contribuem para o desenvolvimento de uma personalidade maquiavélica, Lustosa, Roazzi e Camino (2004, p.60) afirmam:

[...] podemos notar que a escolaridade parece estar relacionada ao Maquiavelismo, uma vez que a literatura psicológica referente a esse construto afirma que o mesmo desenvolvese a partir da socialização secundária. Entretanto, ressalva-se que o Maquiavelismo não é um construto unidimensional, tampouco uma característica definidora por si só da personalidade dos sujeitos, mas deve ser considerado, tendo em vista as circunstâncias de vida dos sujeitos e as interações que estes desenvolvem. 
Objetivando criar um instrumento que mensurasse o nível de Maquiavelismo do indivíduo, ou a Personalidade Maquiavélica, Christi e Geis (1970) desenvolveram a escala Mach IV, que segundo Cunha e Marcelino (2001 apud GROHMANN; BATTISTELLA; COSTA, 2010a) é uma das medidas de uso mais frequente nos estudos sobre comportamento organizacional. A Mach IV é uma escala do tipo Likert, sendo composta por 20 afirmações que dão origem a três dimensões: táticas interpessoais, visão cínica da natureza humana e moralidade abstrata.

De acordo com Grohmann; Battistella e Costa (2010), a utilização de apenas 20 variáveis, para mensurar um construto tão complexo, é um das principais deficiências da Mach IV, além dos problemas relacionados à sua validade estatística, (VLEEMING, 1979; OHAIR; CODY, 1987) que também prejudicam o seu uso.

Propondo suprir as deficiências existentes na escala Mach IV, Dahling, Whitaker e Levy (2009) conceberam uma nova escala de mensuração do perfil maquiavélico: a Machiavellianism Personality Scale (MPS). Os autores propõem a compreensão do perfil maquiavélico como um construto composto a partir de quatro dimensões: descrença nos outros, desejo de status, desejo de controle e manipulação amoral, como pode ser visto na Figura 01 abaixo:

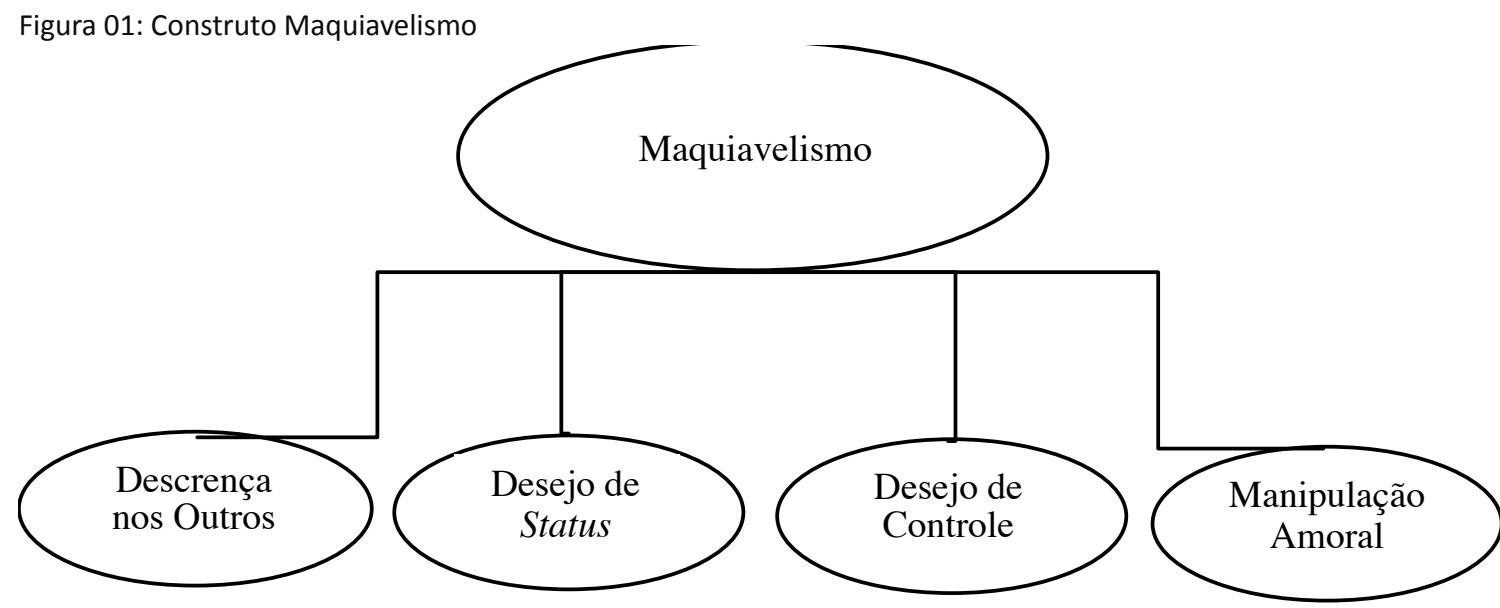

Fonte: Dahling, Whitaker e Levy, (2009)

A descrença nos outros pode ser caracterizada como um "um olhar cínico sobre as motivações e intenções das outras pessoas" (WHITAKER; LEVY, 2009, p. 227). O desejo de status é descrito como sendo "um desejo de acumular indicadores externos de sucesso" (p.228). O desejo de controle é, na visão dos autores, "uma necessidade para exercitar domínio sobre as situações interpessoais, minimizando a extensão do poder dos outros" (p.228). Por fim, a manipulação amoral é caracterizada como "propensão para romper padrões de moralidade e valorizar comportamentos que beneficiem a si próprio à custa dos outros" (p. 228).

Essa personalidade maquiavélica, quando considerada no contexto desta pesquisa (setor lojista), pode ser considerada vantajosa, de acordo com pesquisas já desenvolvidas. Conforme Christie e Geis (1970), indivíduos altamente maquiavélicos possuem vantagens competitivas e superam aqueles menos maquiavélicos quando interagem em situações face a face e quando há espaço para improvisação. Acredita-se ainda que, contar com funcionário maquiavélico pode ser benéfico, pois normalmente seu desempenho é superior, se comparado aos demais colegas (GABLE; TOPOL, 1987).

Segundo Sakalaki, Richardson e Thepaut (2007) pessoas com altos níveis de Maquiavelismo buscam a maximização de lucros, e de acordo com Ricks e Fraedrich (1999) pessoas maquiavélicas são geralmente os melhores vendedores. Maquiavelismo seria, então, característica importante 
no setor lojista, dada a acirrada concorrência e a utilização de metas de vendas desafiadoras.

Outros pesquisadores que relacionam Maquiavelismo e vendas acreditam ser necessários, para um bom vendedor, certo grau de agressividade e manipulação para que consiga fechar vendas (GREEMBERG; MAYER, 1964; CHRISTIE; GEIS, 1970).

A intenção de diversos estudiosos em entender melhor a personalidade maquiavélica e seu impacto no âmbito organizacional, assim como a sua aplicabilidade prática no mundo dos negócios, voltada para o comércio, tem encontrado relação positiva entre Maquiavelismo e desempenho.

\subsection{Maquiavelismo nas Organizações}

No decorrer da evolução dos estudos sobre Maquiavelismo, este construto tem sido definido ora como um traço ou disposição da personalidade (VLEEMING, 1979; MCHOSKEY, 1995), ora com estratégia de conduta social (WILSON; NEAR; MILLER, 1996). No primeiro entendimento, o Maquiavelismo engloba dimensões do comportamento humano de maneira geral e, portanto, também envolve o comportamento organizacional. No segundo entendimento, por se tratar de manipulação interpessoal com o intuito de obter ganhos, diz respeito, mais diretamente, ao desempenho profissional.

Conforme Dahling, Whitaker e Levy (2009), o Maquiavelismo pode ser utilizado nos estudos organizacionais como uma forma de obter melhor compreensão dos aspectos ligados à confiança organizacional, à gestão da ética e às políticas organizacionais.

As principais pesquisas que demonstram a influência do Maquiavelismo no comportamento das pessoas, dentro das organizações, foram realizadas a partir do último quarto do século XX. Esses estudos chegaram a diversas conclusões, tais como: há baixa disposição em ajudar os outros, em indivíduos considerados mais maquiavélicos (WOLFSON, 1981); há relação negativa do Maquiavelismo com a satisfação no trabalho (GABLE; TOPOL, 1987). O quadro a seguir apresenta o resumo das principais relações traçadas entre assuntos organizacionais e Maquiavelismo, identificando as pesquisas e seus autores.

Quadro 01- Maquiavelismo e os Assuntos Organizacionais

\begin{tabular}{|c|c|c|}
\hline Assunto & Principais inferências & Principais pesquisas \\
\hline Liderança & $\begin{array}{l}\text { Lideres têm alto nível de Maquiavelismo não } \\
\text { direto, adaptativo e até carismático, apesar } \\
\text { de seus seguidores não lhes darem suporte. }\end{array}$ & $\begin{array}{l}\text { Deluga (2001), Drory e Glusinkos } \\
(1980)\end{array}$ \\
\hline $\begin{array}{l}\text { Vantagem } \\
\text { econômica }\end{array}$ & $\begin{array}{l}\text { Alto Maquiavelismo é ligado com maximiza- } \\
\text { ção de lucros e pouca recompensa financei- } \\
\text { ras aos parceiros. }\end{array}$ & $\begin{array}{l}\text { Sakalaki, Richardson e Thepaut (2007), } \\
\text { Ricks, Fraedrich (1999), Ross, Robert- } \\
\text { son (2003) }\end{array}$ \\
\hline Trapaça & $\begin{array}{l}\text { Maquiavélicos são mais propensos a tirar } \\
\text { vantagens das oportunidades e estão dispos- } \\
\text { tos a violar a confiança dos outros. }\end{array}$ & $\begin{array}{l}\text { Fehr, Samson e Paulhus (1992), Harrel } \\
\text { e Hartnagel (1976) }\end{array}$ \\
\hline $\begin{array}{l}\text { Influências } \\
\text { Tácitas }\end{array}$ & $\begin{array}{l}\text { Alto nível de Maquiavelismo indica pessoa } \\
\text { que busca influenciar os outros, construir re- } \\
\text { lações políticas e tem atitudes de ingratidão } \\
\text { e intimidação. }\end{array}$ & $\begin{array}{l}\text { Dingler e Brown (1987), Harrel (1980); } \\
\text { Pandey e Rastogi (1979) }\end{array}$ \\
\hline $\begin{array}{l}\text { Satisfação no } \\
\text { trabalho }\end{array}$ & $\begin{array}{l}\text { A satisfação no trabalho tem uma relação ne- } \\
\text { gativa com o nível de Maquiavelismo. }\end{array}$ & $\begin{array}{l}\text { Gable e Topol (1987); Gemmill e Heis- } \\
\text { ler (1972); Hunt e Chonko (1984) }\end{array}$ \\
\hline $\begin{array}{l}\text { Escolha } \\
\text { ocupacional }\end{array}$ & $\begin{array}{l}\text { Maquiavélicos preferem carreiras administra- } \\
\text { tivas ou relacionadas com leis (advogados). }\end{array}$ & $\begin{array}{l}\text { Chonko (1982); Hunt e Chonko (1984); } \\
\text { Steininger e Elisenberg (1976); Wer- } \\
\text { theim, Windom e Wortzel (1978) }\end{array}$ \\
\hline $\begin{array}{l}\text { Comportamentos } \\
\text { de ajuda }\end{array}$ & $\begin{array}{l}\text { Maquiavélicos são menos propensos a aju- } \\
\text { dar os outros. }\end{array}$ & Wolfson (1981) \\
\hline
\end{tabular}


Evidentemente, os estudos sobre Maquiavelismo estão relacionados aos aspectos éticos no comportamento humano e essa preocupação não poderia ser diferente quando o assunto é tratado nos estudos organizacionais. Isso transparece, principalmente quando o Maquiavelismo é estudado em relação a outros assuntos, como se vê no Quadro 01.

Tomando como base o comportamento ético do indivíduo dentro das organizações, Grohmann, Battistella e Costa (2010a) afirmam que, ao longo do tempo, o construto Maquiavelismo tem sido explorado pelos estudos organizacionais, sendo abordados, principalmente, os aspectos relativos à liderança, influências, satisfação, e competição.

Dahling, Whitaker e Levy (2009), defendem o estudo do Maquiavelismo nas organizações como forma de compreender melhor os aspectos ligados à gestão da ética, políticas e confiança organizacional.

É truísmo afirmar que os estudos sobre o comportamento humano devem, necessariamente, levar em consideração as questões culturais e, nessas, principalmente os valores e os limites éticos característicos do espaço geográfico onde acontecem as pesquisas.

Estudos desenvolvidos no Brasil, validando a escala MPS, ressaltam a necessidade de eliminação de algumas de suas variáveis, de modo a adaptá-la à realidade nacional (GROHMANN, BATTISTELLA, COSTA, 2010a). Concordando com os autores, neste estudo, optou-se por partir da versão original da escala, para verificar sua validade e fazer as adaptações indicadas no tratamento estatístico de validação.

\subsection{A Escala de Personalidade Maquiavélica (MPS)}

Desenvolvida por Dahling, Whitaker e Levy (2009), a Machiavellianism Personality Scale (MPS) ou Escala de Personalidade Maquiavélica (EPM) foi elaborada a partir da evolução da Mach IV, tendo em vista os problemas de validação desta escala e de sua contribuição para os estudos de Maquiavelismo. A principal diferença entre as duas escalas encontra-se no fato de que a MPS inclui dimensões do comportamento observável e também de crenças e motivações internas, considerando-se a característica complexa do construto Maquiavelismo conforme afirmam Dahling, Whitaker e Levy (2009). Os autores acreditam que este construto é indicado por quatro dimensões, a saber: descrença nos outros, manipulação amoral, desejo de controle e desejo de status.

A MPS, originalmente composta por 45 itens, teve algumas variáveis eliminadas quando foi validada para aplicação nos Estados Unidos por seus desenvolvedores, restando ao final da pesquisa apenas 16 variáveis na formação dos quatros fatores: cinco variáveis agrupadas representando manipulação amoral; cinco variáveis agrupadas formando o fator descrença nos outros; três variáveis compondo o fator desejo de status e três variáveis agrupadas representando o desejo de controle.

Quando testada no Brasil por Grohmann, Battistella e Costa (2010a), a escala foi validada com 18 itens restantes da escala original, compondo quatro fatores: quatro variáveis agrupadas em amoralidade, seis compondo o fator descrença nos outros; cinco agrupadas em desejo de controle e três em desejo de status. Observe-se que esses autores mantiveram semelhantes aos fatores as mesmas denominações originais.

Uma das contribuições dessa pesquisa, além da validação da escala no país, foi a constatação de que os construtos mais importantes, para a mensuração do Maquiavelismo eram, de acordo com a variância total explicada por cada fator, em ordem decrescente de importância: amoralidade, desejo de controle, desejo de status e descrença nos outros. 
Grohmann, Battistella e Costa (2010b) utilizando a mesma escala, analisaram a relação existente entre Maquiavelismo e gênero, idade e religiosidade ou espiritualidade. No que se refere a gênero a pesquisa detectou que homens têm níveis mais altos de Maquiavelismo do que as mulheres. No tocante a idade, verificou-se que profissionais mais jovens tem níveis mais altos de Maquiavelismo. Quando se analisou a religiosidade, detectou-se que as pessoas religiosas são menos maquiavélicas do que as pessoas não religiosas.

Nesta presente pesquisa, foram realizadas as mesmas análises feitas por Grohmann, Battistella e Costa (2010b), de modo a fornecer instrumento de comparação entre os estudos da MPS na realidade nacional.

\section{METODOLOGIA DA PESQUISA}

A presente pesquisa classifica-se quanto aos meios como quantitativa, que, na visão de Beuren (2008) caracteriza-se por empregar métodos estatísticos tanto na coleta dos dados como na análise dos dados. Quanto aos fins, a pesquisa pode ser compreendida como descritiva, pois não pretende interferir nem seu objeto de estudo. Após a construção do referencial foi realizada uma pesquisa de campo por meio da aplicação de questionários, a gestores e funcionários de lojas da cidade de Fortaleza a fim de alcançar os objetivos estabelecidos.

Na pesquisa de campo foi utilizada uma amostra randômica e probabilística, sendo pesquisados 164 estabelecimentos dentro do universo das lojas de Fortaleza, nas quais, foram inquiridos o gerente e os vendedores de cada loja, totalizando 400 questionários (236 vendedores e 164 gerentes).

$\mathrm{O}$ instrumento de pesquisa estava distribuído em duas partes: a primeira tratava da caracterização sócio-demográfica de cada respondente; a segunda estava composta pelas questões em escala Likert para medição do nível de Maquiavelismo (MPS), contendo 45 itens, dentre os quais 14 itens refletem o construto manipulação amoral, 11 itens medem o desejo de controle, nove itens refletem o construto desejo de status e 11 itens mensuram a não confiança em outras pessoas. Com o intuito de verificar a aplicabilidade e viabilidade do questionário este foi submetido ao pré-teste para verificação de entendimento e facilidade de resposta. Aplicou-se então, um "pacote" de 30 questionários nas lojas da Av. Monsenhor Tabosa, conhecido centro de varejo de Fortaleza. Da quantidade aplicada, 15 foram aplicados com os gerentes e 15 foram aplicados com os vendedores. Em média, os investigados levaram 20 minutos para responder ao instrumento de pesquisa, sem dificuldade de preenchimento.

Depois de aplicados os questionários definitivos, os dados obtidos foram tabulados com uso do software SPSS, versão 18.0. As variáveis 2 , 4, 8, 18, 19, 23, 26, 28, 30, 32, 33 e 37 da escala de Maquiavelismo foram invertidas (recodificadas), tendo em vista seu sentido oposto em relação às demais variáveis. Também como tratamento de preparação dos dados para análise, verificou-se a existência de casos omissos,. Considerando-se a total aleatoriedade destes casos, os missing values foram tratados utilizando o método de substituição pela média dos dados presentes da variável.

Foi feito um tratamento descritivo dos dados obtidos; em seguida realizou-se uma Análise Fatorial Exploratória, de modo analisar a formação do construto. A Análise Fatorial foi um tratamento adequado para a redução das variáveis. Segundo Hair et al (2005), este tratamento analisa a estrutura das inter-relações (correlações) entre um grande número de variáveis definindo um conjunto de dimensões latentes comuns, chamados de fatores. Estes fatores são em menor número que as variáveis originais e passam a ser as novas variáveis a serem tratadas. Os fatores são encontrados para maximizar o poder de explicação do conjunto inteiro de variáveis, e não para prever uma variável dependente. 
Neste estudo, a Análise Fatorial foi utilizada na perspectiva exploratória. Nesta perspectiva ela é útil na busca da estrutura em um conjunto de variáveis ou como um método de redução de dados (HAIR et al, 2005). A Análise Fatorial Exploratória foi utilizada para verificar a formação dos fatores dos construtos Ética e Maquiavelismo.

Posteriormente, foram efetuadas Análises de Variância (ANOVA), para verificar se há diferenças de nível de Maquiavelismo entre os segmentos definidos nas hipóteses: gerentes e vendedores, homens e mulheres, os mais jovens e mais velhos, religiosos e não religiosos.

A ANOVA, conforme Hair et al (2005), é uma técnica estatística para determinar, com base em uma medida dependente, se várias amostras são oriundas de populações com médias iguais. No caso desta pesquisa, a diferença significativa de médias permitiu compreender que há diferença de percepção entre os respondentes, conforme as segmentações adotadas.

\section{ANÁLISE DOS RESULTADOS}

A análise descritiva dos dados demonstrou que, da amostra de 400 sujeitos, 164 eram gerentes e 236 vendedores de lojas. Entre os vendedores e gerentes pesquisados, apenas 30 (7,5\%) eram do gênero masculino, e 370 (92,5\%) eram do gênero feminino. A idade média dos respondentes foi de 28 anos, variando entre 17 e 59 anos, no entanto, a maior frequência encontrou-se na faixa de 17 a 27 anos (52,5\%). Quanto à religiosidade, apenas 20 pessoas declararam que não tinham religião, enquanto 380 declararam-se religiosos, entre praticantes e não-praticantes.

Segundo explicitado anteriormente, nesta pesquisa realizou-se a Análise Fatorial Exploratória (AFE). Para efetuar a AFE, utilizou-se a rotação Varimax, com o intuito de maximizar a soma de variâncias de cargas exigidas na matriz fatorial, bem como a normalização Kaiser, e a Análise dos Principais Componentes.

Para garantir a adequação da aplicabilidade da Análise Fatorial foram realizados os testes de KMO (Kaiser - Meyer - Olkin) e o teste de esfericidade de Bartlett.

Segundo Pestana e Gageiro (2000) um resultado do Teste KMO entre 0,6 e 0,7 indica que os dados são razoavelmente adequados a tratamento por Análise Fatorial. Este teste busca identificar se há correlação entre as variáveis. O resultado do teste KMO foi de 0,749 , comprovando a existência da correlação entre as variáveis e a adequabilidade do tratamento.

A utilização dessa ferramenta de análise também estaria justificada, considerando-se que o teste de esfericidade de Bartlett retornou significância igual a zero.

Na Análise Fatorial Exploratória foi imposta a restrição de se considerarem apenas as variáveis com comunalidades a partir de 0,5 . Isto resultou na eliminação de 28 delas, passandose de 45 para 17 variáveis, divididas em cinco fatores, como pode ser visto na Tabela 1 a seguir.

A variância total explicada neste modelo foi de 52,806\%, e o Alpha de Cronbach, que avalia a consistência interna da escala, retornou um valor de 0,672 . Conforme Pestana e Gageiro (2000), um Alpha de Cronbach entre 0,6 e 0,7 indica que há razoável consistência interna e que a escala pode ser considerada fiável. Ainda sobre o Alpha de Cronbach, Kline (1999 apud FIELD, 2009) afirma que, em se tratando de construtos psicológicos, valores abaixo de 0,7 podem ser esperados, devido à diversidade dos construtos que estão sendo medidos. 
Tabela 1 - Análise Fatorial Maquiavelismo

\begin{tabular}{|c|c|c|c|c|c|}
\hline \multirow[b]{2}{*}{ Variáveis } & \multicolumn{5}{|c|}{ Fatores } \\
\hline & Amoralidade & \begin{tabular}{|c|} 
Influência \\
Interpessoal
\end{tabular} & \begin{tabular}{c|} 
Desejo \\
de Status
\end{tabular} & $\begin{array}{l}\text { Drescrença } \\
\text { nos Outros }\end{array}$ & $\overline{\text { Individualismo }}$ \\
\hline 20. Eu realmente só presto atenção no que as pessoas dizem para & ,508 & & & & \\
\hline $\begin{array}{l}\text { descobrir se elas sabem algo que pode me atingir } \\
\text { 36. Eu acredito que mentir é necessário para ter vantagem } \\
\text { competitiva }\end{array}$ & 629 & & & & \\
\hline 39. A única boa razão para falar com os outros é conseguir & ,718 & & & & \\
\hline informações que eu possa usar para me beneficiar & & & & & \\
\hline $\begin{array}{l}\text { 44. Eu estou disposto a sabotar os esforços dos outros se isso } \\
\text { estiver prejudicando meus objetivos }\end{array}$ & ,764 & & & & \\
\hline 45. Eu poderia trapacear se houvesse pouca chance de ser pego & ,734 & & & & \\
\hline $\begin{array}{l}\text { 29.Eu acho que medo e ameaças são coisas necessárias para motiva } \\
\text { as pessoas a fazerem o que eu quero }\end{array}$ & ,605 & & & & \\
\hline 24. Eu estou disposto a ser não ético se isso me ajudar a ter sucesso &, 546 & & & & \\
\hline 12. Eu sei ser charmoso quando preciso ser & & 697 & & & \\
\hline 31. Eu consigo administrar a forma como os outros me vêem & &, 573 & & & \\
\hline $\begin{array}{l}\text { 42. Eu sei como me apresentar para ser visto como eu quero ser } \\
\text { visto }\end{array}$ & & ,624 & & & \\
\hline 6. Status é um bom sinal de sucesso na vida & & & 620 & & \\
\hline 10. Acumular bens é um importante objetivo para mim & & & ,808 & & \\
\hline 34. Eu quero ser rico e poderoso algum dia & & &, 533 & & \\
\hline $\begin{array}{l}\text { 3. Se eu mostrar qualquer fraqueza no trabalho, os outros tirarão } \\
\text { vantagens disso }\end{array}$ & & & & ,638 & \\
\hline 27. As pessoas só são motivadas por objetivos pessoais & & & & ,646 & \\
\hline $\begin{array}{l}\text { 15. Quando eu tenho uma ideia promissora, eu a mantenho comigo, } \\
\text { a fim de evitar que os outros a roubem }\end{array}$ & & & & & ,743 \\
\hline 23. Eu gosto de dividir meus planos e idéias com outras pessoas (I) & & & & & ,719 \\
\hline
\end{tabular}

Dos cinco fatores originados pelo modelo final da escala, resultante da Análise Fatorial Exploratória (com 17 variáveis), três permaneceram com a nomenclatura original (Amoralidade, Desejo de Status e Descrença nos outros), e dois tiveram que ser renomeados (Influência Interpessoal e Individualismo), levando-se em consideração as variáveis agrupadas.

O fator Amoralidade foi o fator que concentrou o maior número de variáveis (sete), sendo uma delas (Q.29) pertencente originalmente construto desejo de controle. A Amoralidade explicou $18,57 \%$ do modelo.

O segundo fator gerado na análise foi denominado como Influência Interpessoal. Este, por sua vez, foi constituído de variáveis que a priori pertenciam aos construtos amoralidade ( $\mathrm{Q}$. 12 e 42) e descrença nos outros (Q. 31). No entanto, as referidas variáveis agrupadas refletem o sentido de habilidade de influenciar outras pessoas. A explicação da formação deste fator pode estar na atividade dos sujeitos da pesquisa, por serem pessoas que necessitam daquela habilidade para atuar profissionalmente. A influência interpessoal explica $12,46 \%$ da variância total.

Desejo de Status foi o terceiro fator formado. Este explica 7,79\% do modelo, e foi constituído pelas mesmas variáveis da escala original (DAHLING; WHITAKER; LEVY, 2009).

Os dois últimos fatores formados estão compostos, fundamentalmente, por variáveis do construto Descrença nos Outros, tendo o quarto fator recebido este mesmo nome, e explicado $7,44 \%$ da variância. Por conseguinte, o quinto fator deveria receber outra denominação, tendo-se escolhido Individualismo, pois denota um espírito mais egoísta, o que pode ser considerado um achado de pesquisa e pode ser explicado pela atividade profissional dos respondentes. Este fator explica $6,53 \%$ do modelo. 
Curiosamente, o construto "Desejo de Controle" não aparece neste trabalho. Esta não ocorrência, provavelmente, se deve ao fato de que os inquiridos desenvolvem suas atividades individualmente e, de um modo geral, não precisam controlar as demais pessoas para desenvolvê-las.

Após realizar a Análise Fatorial, verificou-se o nível de Maquiavelismo dos integrantes do setor lojista. Constatou-se que a média total das questões retornou valor de 2,69, o que pode ser considerado um nível médio de Maquiavelismo, uma vez que a escala variava de 1 a 5 . Vendedores e gerentes também demonstraram médias similares ao valor da média total, de acordo com a Tabela 2 que segue.

Tabela 2 - Nível de Maquiavelismo

\begin{tabular}{ccc}
\hline Cargo & Média & Desvio Padrão \\
\hline Vendedor & 2,69 & 1,350 \\
\hline Gerente & 2,70 & 1,346 \\
\hline Total & 2,69 & 1,348 \\
\hline \multicolumn{2}{c}{ Fonte: Dados da Pesquisa } \\
\hline
\end{tabular}

Para efetuar as análises das hipóteses procedeu-se ao tratamento de Análise de Variância (ANOVA) que, de acordo com Hair et al (2005), é utilizada para avaliar a significância estatística de diferentes grupos. $O$ critério para a análise foi o valor limite de sig $<0,05$. Também conforme o autor, na ANOVA a hipótese nula testada é a igualdade de médias da variável dependente ao longo de grupos.

Ao analisar a Hipótese 1 - Os gestores são mais maquiavélicos do que seus funcionários (Tabela 3), verifica-se que não se pode rejeitar a hipótese nula, tendo em vista que o teste obteve significância entre as diferenças de médias do grupo vendedores/gerentes maiores que 0,05, para todos os construtos.

Tabela 3 - ANOVA $\mathrm{H}_{1}$

\begin{tabular}{lcccc}
\hline Variáveis & Média Vendedores & Médias Gerentes & $\mathrm{F}$ & Sig. \\
\hline Amoralidade & $-0,0011873$ & 0,0017085 & 0,001 & 0,977 \\
Influência Interpessoal & $-0,0004941$ & 0,0007111 & 0,000 & 0,991 \\
Status & 0,0098416 & $-0,0141623$ & 0,056 & 0,814 \\
Descrença nos Outros & $-0,0394138$ & 0,0567175 & 0,894 & 0,345 \\
Individualismo & 0,0396953 & $-0,0571225$ & 0,907 & 0,342 \\
\hline
\end{tabular}

Fonte: Dados da Pesquisa

Portanto não se pode afirmar que os gestores (gerentes) são mais maquiavélicos do que seus funcionários (vendedores).

Quando se relacionou Maquiavelismo e gênero, verificou-se que a hipótese nula deve ser rejeitada, uma vez que se encontrou diferença significativa de médias entre os grupos (Tabela 4). 
Tabela 4 - ANOVA $\mathrm{H}_{2}$

\begin{tabular}{lcccl}
\hline Variáveis & Média Homens & Média Mulheres & $\mathrm{F}$ & Sig. \\
\hline Amoralidade & 0,52444448 & $-0,0425225$ & 9,101 & 0,003 \\
Influência Interpessoal & $-0,2748777$ & 0,0222874 & 2,459 & 0,118 \\
Status & 0,1475110 & $-0,0119603$ & 0,705 & 0,402 \\
Descrença nos Outros & 0,0291808 & $-0,0023660$ & 0,028 & 0,868 \\
Individualismo & 0,2586224 & $-0,0209694$ & 2,176 & 0,141 \\
\hline
\end{tabular}

Fonte: Dados da Pesquisa

Deste modo, pode-se dizer que, em consonância com o encontrado por Grohmann, Battistella e Costa (2010b), há diferença de nível de Maquiavelismo entre gêneros. Na presente pesquisa, a diferença significativa de média $(\mathrm{Sig}<0,05)$ concentrou-se no construto Amoralidade, apresentando os homens $(0,52)$, média mais elevada do que as mulheres $(-0,042)$, o que corrobora $\mathrm{H}_{2}$, não sendo possível rejeitá-la, embora se deva registrar que em Influência Interpessoal, os homens apresentaram média menor que as mulheres $(-0,27$ versus 0,02$)$.

A análise da Tabela 5 a seguir, demonstra que não há diferença significativa de percepção de Maquiavelismo entre mais jovens e mais velhos, o que contribui para a não rejeição da hipótese nula, e a rejeição de $\mathrm{H}_{3}$, possibilitando afirmar que a idade não influencia no nível de Maquiavelismo das pessoas, para a amostra estudada.

Tabela 5 - ANOVA $\mathrm{H}_{3}$

\begin{tabular}{lccccccl}
\hline & Média Idade & Média Idade & Média Idade & Média Idade & & \\
Variáveis & 17 a 27 anos & 28 a 38 anos & 39 a 49 anos & 50 a 59 anos & F & Sig. \\
\hline Amoralidade & 0,0761952 & $-0,0707534$ & $-0,0588016$ & $-0,6588132$ & 1,427 & 0,235 \\
Influência Interpessoal & 0,0169252 & 0,0565895 & $-0,2646476$ & $-0,7487560$ & 1,877 & 0,133 \\
Status & 0,1084840 & $-0,0934775$ & $-0,2110101$ & $-0,3454500$ & 1,957 & 0,120 \\
Descrença nos Outros & $-0,0355589$ & $-0,0352839$ & 0,3192185 & 0,5301626 & 1,717 & 0,163 \\
Individualismo & 0,0138102 & 0,0237064 & $-0,2313391$ & 0,1751261 & 0,662 & 0,576 \\
\hline Fon
\end{tabular}

Fonte: Dados da Pesquisa

Ao passo que se analisou a religiosidade e sua relação com o Maquiavelismo, evidenciou-se que não houve diferença significativa de média entre o grupo de pessoas religiosas e o grupo de pessoas não-religiosas (TAB.6), na amostra.

Tabela 6 -ANOVA $\mathrm{H}_{4}$

\begin{tabular}{llrrl}
\hline Variáveis & Religioso & Não-religioso & F & Sig. \\
\hline Amoralidade & $-0,0145614$ & 0,2766675 & 1,614 & 0,205 \\
Influência Interpessoal & $-0,0065031$ & 0,1235582 & 0,321 & 0,571 \\
Status & $-0,0201995$ & 0,3837912 & 3,117 & 0,078 \\
Descrença nos Outros & $-0,0159947$ & 0,3038986 & 1,949 & 0,163 \\
Individualismo & $-0,0040089$ & 0,0761698 & 0,122 & 0,727 \\
\hline
\end{tabular}

Fonte: Dados da Pesquisa

Este resultado corrobora a hipótese nula e rejeita $\mathrm{H}_{4^{\prime}}$ não tendo sido evidenciada a influência da religiosidade nos níveis de Maquiavelismo dos profissionais de comércio na amostra pesquisada. 


\section{CONSIDERAÇÕES FINAIS}

Esta pesquisa analisou a formação do construto Maquiavelismo, sendo o arcabouço teórico embasado a partir dos preceitos de Maquiavel (1982), estabelecidos na sua obra O Príncipe. Sua principal contribuição se deu de duas formas: contribuição acadêmica e empresarial; colabora para o esclarecimento e a desmistificação do construto "Maquiavelismo".

O objetivo geral do trabalho foi alcançado quando se obteve a formação dos cinco fatores do maquiavelismo (Amoralidade, Influência Interpessoal, Status, Descrença do Outros e Individualismo). O teste das hipóteses norteadoras da pesquisa solidificou os resultados do estudo, conforme segue:

Das quatro hipóteses do estudo, uma não foi rejeitada $\left(\mathrm{H}_{2}\right.$ : Os homens são mais maquiavélicos do que as mulheres) e três foram rejeitadas $\left(\mathrm{H}_{1}\right.$ : Os gestores são mais maquiavélicos do que seus funcionários; $\mathrm{H}_{3}$ : Os mais jovens são mais maquiavélicos do que os mais velhos; e $\mathrm{H}_{4}$ : Os que não são religiosos são mais maquiavélicos do que os religiosos). Constatou-se, portanto, que o gênero está inter-relacionado com o Maquiavelismo, o que não foi constatado para os aspectos de religiosidade, idade e cargo (para gerentes e vendedores).

Os resultados alcançados neste trabalho demonstram a aplicabilidade da escala utilizada, assim como ratifica, em parte, a composição do construto. Como dito anteriormente, as análises estatísticas evidenciaram a formação de cinco fatores formadores do Maquiavelismo (Amoralidade, Influência Interpessoal, Status, Descrença no outros e Individualismo).

A partir dos resultados apresentados neste estudo, podem-se traçar estratégias para o melhor gerenciamento das atividades de vendedores e gerentes do comércio lojista, de modo a melhorar as relações interpessoais destes profissionais e, por consequência, aperfeiçoar as técnicas de venda, uma vez que se conhece mais como estes trabalhadores se comportam.

Apesar dos resultados e contribuições da pesquisa, este trabalho apresenta limitações, tais como a concentração geográfica, haja vista que se pesquisaram apenas integrantes do setor lojista de Fortaleza, sendo pertinente, em próximas pesquisas, pesquisar profissionais de outras regiões do país.

Por fim, apesar das limitações citadas, esta pesquisa serve como subsídio para novas investigações sobre a compreensão do Maquiavelismo nos negócios. Para um maior entendimento e abrangência das relações evidenciadas neste trabalho, faz-se importante a aplicação de outros instrumentos com diferentes amostras compostas em diferentes estados, diferentes setores da economia, e com outras profissões.

\section{REFERÊNCIAS}

ALBUQUERQUE, L. C. FERREIRA, K. V. D. Efeitos de regras com diferentes extensões sobre o comportamento humano. Psicologia Reflexão e Crítica [online]. 2001, vol.14, n.1, pp. 143155. Disponível em http://www.scielo.br/pdf/ prc/v14n1/5214.pdf. Acesso em 30 nov 2010.

BARROS, D. F. Homem Múltiplo. In: Discutindo Filosofia especial: Maquiavel. Ano 1, n 42008.

BEUREN, I. M (Org.). Como elaborar trabalhos monográficos em Contabilidade - Teoria e prática. São Paulo: Atlas, 2008.
CANDEIAS, N. M. F. Conceitos de educação e de promoção em saúde: mudanças individuais e mudanças organizacionais, In Rev. Saúde Pública v 31, n 2, São Paulo, Abril, 1997.

CHANLAT, Jean F. Por uma Antropologia da Condição Humana nas Organizações In 0 Indivíduo na Organização, v 1 Atlas, 1996.

CHISTIE, S., GEIS, F. Studies in Machiavellianism. San Diego: Academic Press, 1970.

DAHLING, J.; WHITAKER, B.; LEVY, P. The Development and Validation of a New Machiavellianism Scale. Journal of Management, v. 35, p. 219-257, 2009. 
FIELD, ANDY. Descobrindo a estatística usando o SPSS. 2 ed. Porto Alegre: ArtMed, 2009.

GABLE, M. TOPOL, M. Job satisfaction and Machiavellian orientation among department store executives. Psychological Reports, n 60 p. 211-216, 1987.

GUNNTHORSDOTTIR, A., MCCABE, K., SMITH, V. Using the Machiavellianism instrument to predict trustworthiness in a bargaining game. Journal of Economic Psychology, v 23, n 1, p. 49-66, 2002.

GROHMANN, M.Z.; BATTISTELLA, L.S.; COSTA, V.M.F. A Escala de Personalidade Maquiavélica - MPS: validação para o contexto nacional. In: XXXIV Encontro da ANPAD. Anais... Rio de Janeiro, 2010.

GROHMANN, M.Z.; BATTISTELLA, L.S.; COSTA, V.M.F. Machiavelismo Revisitado: estudo em uma organização hospitalar. In: VI Encontro da Divisão de Estudos Organizacionais da ANPAD. Anais... Florianópolis, 2010.

HAIR, J. F.; ANDERSON, R. E.; TATHAM, R. L.; BLACK, W. C. Análise multivariada de dados. Porto Alegre: Bookman, 2005.

HOUAISS, Antônio. Dicionário da Língua Portuguesa. 2001. CD-ROM.

LUSTOSA, A.V.M.F. ROAZZI, A.; CAMINO, C. Maquiavelismo: um construto psicológico. Estudos e Pesquisas em Psicologia, n 4 v. 1, 2004.

MARTINS, J. A. Além do Maquiavelismo. In: Discutindo Filosofia especial: Maquiavel. Ano 1, n.4, 2008.

MAQUIAVEL, Nicolau. O Príncipe. Rio de Janeiro: Civilização Brasileira, 1982.

PESTANA, M.; GAGEIRO, J. Análise de dados para ciências sociais: a complementaridade do SPSS. Lisboa: Gráfica Rolo e filhos, 2000.

RICKS, J. FRAEDRICH, J. (1999) The paradox of Machiavellianism: Machiavellianism may mala for productive sales but poor management reviews. Journal of Business Ethics, n. 20, p. 197-205.

SANCHES, M. A. SCARPI, M. J. Ética organizacional: um estudo em clínicas oftalmológicas. Arq. Bras. Oftalmol. [online]. v. 68, n.6, p. $807-813,2005$. Disponível em http://www.scielo.br/scielo. Acesso 30 nov 2010.

VLEEMING, R.G. Machiavellianism: a preliminary review. Psychological Reports, v. 44, p. 295-310, 1979.

WILSON, D.S. NEAR, D. MILLER, R.R. Machiavellianism: a synthesis of the Evolutionary and Psychological Literatures. Psychological Bulletin, v 119, n 2, p. 285-299, 1996.

WOLFSON, S. L. Effects of Machiavellianism and communication on helping behaviour during an emergency. British Journal of Social Psychology, n 4 p. 328-332, 1981. 